\title{
Avoidance of unnecessary fine-needle aspiration with the use of the Thyroid Imaging Reporting Data System classification and strain elastography based on The Bethesda System for Reporting Thyroid Cytopathology
}

\author{
MURAT ERKAN $^{1}$, SULE CANBERK ${ }^{1,4}$, GAMZE Z. KILICOGLU ${ }^{2}$, MINE ONENERK ${ }^{1}$, \\ ATAY ULUDOKUMACI ${ }^{3}$, PEMBEGUL GUNES ${ }^{1}$ and TUGBA ATASOY ${ }^{2}$

\begin{abstract}
Departments of ${ }^{1}$ Pathology-Cytopathology, and ${ }^{2}$ Radiology, Interventional Radiology Unit, Haydarpasa Numune Training and Research Hospital; ${ }^{3}$ Department of Pathology, Bagcilar Training and Research Hospital, Istanbul, Turkey
\end{abstract}

Received April 8, 2016; Accepted July 7, 2016

DOI: $10.3892 / \mathrm{mco} .2016 .1003$

\begin{abstract}
Thyroid fine-needle aspiration (FNA) biopsy has been widely accepted as an accurate and cost-effective tool in the management of thyroid nodules. To avoid unnecessary FNAs and provide appropriate management, patient evaluation should be based on a multidisciplinary approach. For this purpose, the Thyroid Imaging Reporting and Data System (TI-RADS) and strain elastography (SE) were proposed as tools for the risk assessment of malignancy in thyroid nodules. The aim of the present study was to analyze the utility of TI-RADS system and SE, along with FNA, and prospectively evaluate 369 consecutive patients referred for FNA of a thyroid nodule. TI-RADS was tested against The Bethesda System for Reporting Thyroid Cytopathology to determine whether there was an agreement between the two classification systems; statistically, some agreement was observed. Medians of the maximum SE values (E-max) were obtained for benign and malignant FNA results and found to be 1.97 [interquartile range (IQR): 1.87] and 2.8 (IQR: 3.42), respectively ( $\mathrm{P}=0.004)$. The number of studies investigating the utility of TI-RADS and SE along with TBSRCT is currently limited. Our study demonstrated that a multidisciplinary approach with the use of TI-RADS and SE may mildly improve the management of thyroid nodules.
\end{abstract}

\section{Introduction}

The incidence of thyroid nodules has significantly increased over the last decades (1). Thyroid nodules may be detected in

Correspondence to: Dr Sule Canberk, ${ }^{4}$ Present address: Department of Pathology and Cytopathology, Acibadem Pathology Laboratory, Acıbadem University, 32 Kaydışdagi cad, Istanbul 34752, Turkey

E-mail: sulecanberk@gmail.com

Key words: thyroid fine-needle aspiration, Bethesda, Thyroid Imaging Reporting and Data System, elastography
$19-67 \%$ of the cases by high-resolution ultrasound, and thyroid cancer must be excluded in all these nodules (2). Thyroid nodules are mostly benign and asymptomatic and, thus, do not require any treatment. Fine-needle aspiration (FNA) has become an essential diagnostic modality in the evaluation of thyroid nodules and is implicated in all three major guidelines in patient management, namely the American Thyroid Association (ATA), the European Thyroid Association (ETA) and the Society of Radiologists in Ultrasound (SRU) (3); however, there is currently no consensus regarding the exact indications of FNA in these three main guidelines. The Bethesda System for Reporting Thyroid Cytopathology (TBSRTC), which was created through multidisciplinary formulation, is the most popular cytology reporting system worldwide (4).

The primary success of TBSRTC was reducing unnecessary thyroid surgery. The malignancy detection rate increased from 14 to $50 \%$ prior to and following adoption of FNA as a diagnostic modality, respectively, and was even higher after the introduction of TBSRTC (5). However, the effectiveness of TBSRTC in reducing unnecessary and repeat FNAs, which was the secondary aim, appears to be limited. TBSRTC appears to lack solid support by the main guidelines due to the lack of standardization and clear-cut indications of FNA $(3,6)$. US scoring systems have been devised in an attempt to overcome this weakness. Despite its high diagnostic ability and cost-effectiveness, TBSRTC may be becoming a screening test, which may be associated with high cost rates due to the significant number of FNAs performed in daily routine practice; moreover, it may increase false-positive results in cytological specimens and false-negative/vanishing tumor diagnosis in pathological specimens $(6,7)$.

A number of different imaging modalities have been used to evaluate thyroid nodules to avoid unnecessary FNA and surgery. The Thyroid Imaging Reporting and Data System (TI-RADS) was introduced in 2009 by Horvath et al (8), based on the concepts of the Breast Imaging Reporting and Data System, which conducts a risk assessment of malignancy in breast FNAs. Horvath et al proposed 10 characteristics, and Park et al (9) subsequently established a new system with 12 characteristics, 
which were aimed at standardizing the evaluation of thyroid nodules with US. However, the application of those characteristics to all thyroid nodules was found to be problematic.

Sonoelastography, first proposed in 1991 by Ophir et al, operates on the relative hardness of the nodule compared with the adjacent thyroid parenchyma to improve diagnostic accuracy $(7,10)$. There are two technically different methods, both aimed at measuring the stiffness of the tissues: Strain and shear-wave elastography. Strain elastography (SE) consists of a quantitative measure (strain index) and a qualitative color picture superimposed on the B-mode image. The proof of elevated/increased stiffness should guide FNA, even in nodules without suspicious findings on ultrasound (11).

Therefore, the main question is which nodules should be referred for FNA, which was addressed by investigating 369 cases using TI-RADS and SE with TBSRTC.

\section{Materials and methods}

Case selection. The study was designed to include prospective FNA diagnostics in patients with nodules/focal lesions of the thyroid gland, who were referred for biopsy to the Haydarpasa Numune Training and Research Hospital (Istanbul, Turkey) between January and June, 2014. All aspects of the study were reviewed and approved by the hospital's Institutional Review Board. A total of 369 cases were evaluated by 3 radiologists (with 17, 2 and 16 years of experience) and FNAs were performed. Using the recorded images, a single radiologist determined the corresponding TI-RADS category (Horvath) (Table I).

Procedures. All the patients were ultrasonographically examined (iU22 ultrasound device; Philips, Bothell, WA, USA), elastography was performed and the strain ratio was recorded. Heterogeneous thyroid parenchyma, substernal elongation of the nodule or recurrent nodules following partial/total thyroidectomy hinder elastographic measurement due to the lack of proper reference/background tissue and a maximum SE value (E-max) could not be provided for these cases.

FNAs were performed with a 22-gauge needle and two smears were prepared for each pass. Rapid on-site evaluation was performed by a cytopathologist using Diff-Quik stain. Cell blocks were prepared from the excess material in the syringe. All the cases were signed by the same cytopathologist according to TBRSTC.

Statistical analysis. Statistical analysis was performed using the SPSS software, version 20 (IBM SPSS, Armonk, NY, USA). The variables were investigated using visual or analytical methods to determine whether they were normally distributed. As the E-max value was not normally distributed, the Mann-Whitney U test was conducted to compare values among TBSRTC categories. The agreement between TI-RADS and TBSRTC was tested by using Cohen's Kappa statistics. An overall 5\% type-1 error level was used to infer statistical significance.

\section{Results}

Patient characteristics. A total number of 369 thyroid FNA cases performed between January and June, 2014 were included in the present study. The majority $(86.7 \%$; $\mathrm{n}=320$ ) of the patients were female and the mean age of the patients \pm standard deviation was $56.9 \pm 11$ years. According to TBSRTC, $17.1 \%(\mathrm{n}=63), 59.3 \%(\mathrm{n}=219), 7.1 \%(\mathrm{n}=26), 5.1 \%$ $(n=19), 2.7 \%(n=10)$ and $8.7 \%(n=32)$ of the cases were reported as non-diagnostic (ND), benign (B), atypia of undetermined significance/follicular lesion of unknown significance, follicular neoplasia/suspicious for follicular neoplasia, suspicious for malignancy (SFM) and malignant (M), respectively. The same cases were evaluated as category $2(39 \%$; $n=144)$, category $3(4.1 \%$; $n=15)$, category $4(45 \% ; n=166)$ and category 5 $(1.6 \% ; n=6)$ according to TI-RADS (Table II). A total of $13.8 \%$ $(n=51)$ of the patients underwent consequent thyroidectomy, and the subsequent histopathological diagnosis was benign in $39.2 \%(n=20)$ and malignant in $70.8 \%(n=31)$ of the cases. Malignant diagnosis included 30 papillary thyroid carcinomas (6 classic, 4 encapsulated follicular, 4 aggressive, 7 follicular, 8 oncocytic and 1 Warthin-like variants) and 1 medullary thyroid carcinoma. There was no discrepancy between cytopathological and histopathological diagnosis. The distribution of the cases according to TBRSCT in each TI-RADS category is summarized in Table III. There was some agreement between the TI-RADS and TBRSCT classification systems (32.5\%) and the kappa value for benign and malignant diagnosis was 0.1 . In $16 \%(\mathrm{n}=59)$ of the cases, E-max value could not be provided due to the lack of normal thyroid parenchyma due to multinodular goiter and chronic lymphocytic thyroiditis. For the evaluated cases, the median E-max value for benign nodules was 1.97 [interquartile range (IQR): 1.87], whereas in SFM and $\mathrm{M}$ nodules it was 2.8 (IQR: 3.42), and the difference was found to be statistically significant $(\mathrm{P}=0.004$; Fig. 1$)$.

\section{Discussion}

Walfish et al (12) first proposed ultrasonography (US)-guided FNA in 1977; since then, US-guided FNA has significantly accelerated daily practice. The following US characteristics are widely used to highlight the risk of malignancy in thyroid nodules: Vascularity, microcalcifications, composition, echogenity, margins, presence of a peripheral halo and calcifications. There has been a general consensus/agreement in ATA, ETA or SRU, that suspicious US characteristics are an indication for FNA $(2,6,13,14)$. However, those guidelines have various combinations of suggestions in evaluating malignancy of thyroid nodules that may cause confusion between clinicians. Recently, to establish a better communication between radiologists and clinicians, several US proposals and/or scoring systems have been proposed in the literature $(9,15)$.

TI-RADS was introduced by Horvath et al in 2009 to create a standardized reporting system, inspired by BIRADS, based on the malignancy risk assessment of thyroid nodules (8). At the beginning, TI-RADS appeared to be promising through focusing not only on benign nodules, but also on follicular lesions. The main disadvantages of TI-RADS were difficulty in evaluating 10 US parameters for every nodule, and its complexity that does not provide a clear discrimination for the malignancy risk assessment, let alone focusing on follicular lesions. Over time, TI-RADS was modified by a number of authors in several studies. Park et al proposed a new system 
Table I. US patterns in each TI-RADS (Horvath) category and clinical recommendations based on these categories.

\begin{tabular}{|c|c|c|c|c|}
\hline Description of US pattern & US patterns & Malignancy & TI-RADS & Recommendation \\
\hline $\begin{array}{l}\text { Echoic with hyperechoic spots, } \\
\text { non-vascularized lesion }\end{array}$ & Colloid type 1 & $0 \%$ & $\begin{array}{l}\text { TI-RADS 2: } \\
\text { Benign findings }\end{array}$ & $\begin{array}{l}\text { Follow-up } \\
\text { without FNA }\end{array}$ \\
\hline $\begin{array}{l}\text { Non-encapsulated, mixed, non- } \\
\text { expansile, with hyperechoic spots, } \\
\text { vascularized lesion, grid aspect } \\
\text { (spongiform nodule) }\end{array}$ & Colloid type 2 & & & \\
\hline $\begin{array}{l}\text { Non-encapsulated, mixed with solid } \\
\text { portion, isoechogenic, expansile, } \\
\text { vascularized nodule with } \\
\text { hyperechoic spots }\end{array}$ & Colloid type 3 & & & \\
\hline $\begin{array}{l}\text { Hyper-, iso-, or hypoechoic, partially } \\
\text { encapsulated nodule with peripheral } \\
\text { vascularization, in Hashimoto's } \\
\text { thyroiditis }\end{array}$ & $\begin{array}{l}\text { Hashimoto } \\
\text { pseudonodule }\end{array}$ & $<5 \%$ & $\begin{array}{l}\text { TI-RADS } 3: \\
\text { Likely benign }\end{array}$ & $\begin{array}{l}\text { Follow-up, FNA } \\
\text { may be performed } \\
\text { according to } \\
\text { clinical suspicion }\end{array}$ \\
\hline $\begin{array}{l}\text { Solid or mixed hyper-, iso-, or } \\
\text { hypoechoic nodule, with a thin } \\
\text { capsule }\end{array}$ & $\begin{array}{l}\text { Simple neoplastic } \\
\text { pattern }\end{array}$ & $5-10 \%$ & $\begin{array}{l}\text { TI-RADS 4A: } \\
\text { Undetermined }\end{array}$ & FNA \\
\hline $\begin{array}{l}\text { Hypoechoic lesion with ill-defined } \\
\text { borders, without calcifications }\end{array}$ & de Quervain pattern & & & \\
\hline $\begin{array}{l}\text { Hyper-, iso-, or hypoechoic, } \\
\text { hypervascularized, encapsulated } \\
\text { nodule with a thick capsule, } \\
\text { containing calcifications (coarse or } \\
\text { microcalcifications) }\end{array}$ & $\begin{array}{l}\text { Suspicious } \\
\text { neoplastic pattern }\end{array}$ & & & \\
\hline $\begin{array}{l}\text { Hypoechoic, non-encapsulated } \\
\text { nodule, with irregular shape and } \\
\text { margins, penetrating vessels, with or } \\
\text { without calcifications }\end{array}$ & $\begin{array}{l}\text { Malignant } \\
\text { pattern A }\end{array}$ & $10-80 \%$ & $\begin{array}{l}\text { TI-RADS 4B: } \\
\text { Suspicious }\end{array}$ & FNA \\
\hline $\begin{array}{l}\text { Iso- or hypoechoic, non-encapsulated } \\
\text { nodule with multiple peripheral } \\
\text { microcalcifications and } \\
\text { hypervascularization }\end{array}$ & $\begin{array}{l}\text { Malignant } \\
\text { pattern B }\end{array}$ & $>80 \%$ & $\begin{array}{l}\text { TI-RADS 5: } \\
\text { Consistent } \\
\text { with malignancy }\end{array}$ & FNA \\
\hline $\begin{array}{l}\text { Non-encapsulated, isoechoic, mixed } \\
\text { hypervascularized nodule with or } \\
\text { without calcifications, without } \\
\text { hyperechoic spots }\end{array}$ & $\begin{array}{l}\text { Malignant } \\
\text { pattern } \mathrm{C} \text { cancer, } \\
\text { confirmed by } \\
\text { previous biopsy }\end{array}$ & $100 \%$ & $\begin{array}{l}\text { TI-RADS 6: } \\
\text { Malignant }\end{array}$ & \\
\hline
\end{tabular}

US, ultrasonography; TI-RADS, Thyroid Imaging Reporting and Data System; FNA, fine-needle aspiration.

based on 12 US characteristics (9). Another modified TI-RADS was introduced by Kwak et al (15), which appeared to have a more practical basis on 5 US characteristics compared with the previous versions.

The present study was designed to compare the compatibility and feasibility of the Horvath TI-RADS with TBSRTC and its usefulness for avoiding unnecessary FNAs with the contribution of elastography. Kwak et al reported the increased malignancy risk in correlation with an increased number of suspicious US characteristics (15). Friedrich-Rust et al (16) reported promising results in terms of interobserver agreement with 3 observers for 114 thyroid nodules, but still point out the need for further studies to create an optimal system integrating all TI-RADS categories. The negative predictive value (NPV) was $92-100 \%$ for TI-RADS categories 4 and 5 in the diagnosis of malignancy in the same study.

Our study also demonstrated some agreement between every category of the TI-RADS system and TBSRTC. The suggested malignancy risks were $5-10 \%$ and $10-80 \%$ in categories $4 \mathrm{a}$ and $4 \mathrm{~b}$ of Horvath TI-RADS, respectively, which were compatible with our results in TI-RADS 4a and 4b (10.2-26\%). Our malignancy ratio in TI-RADS 2 was $5.5 \%$ while Horvath's was $0 \%$. Compared with other modified TI-RADS, Horvath's proposal appears to be quite strict $(8,9,15)$ Hence, further large-scale studies are required on this topic. ND and benign cytology results represented marked cumulation in the TI-RADS 4a group that may have originated from external and internal changes of the nodule: Recently, Eze et al stated 
Table II. Patient characteristics.

\begin{tabular}{|c|c|}
\hline Characteristics & No. $(\%)$ \\
\hline \multicolumn{2}{|l|}{ Gender } \\
\hline Female & $320(86.7)$ \\
\hline Male & $49(13.3)$ \\
\hline \multicolumn{2}{|l|}{ Age, years } \\
\hline Mean (range) & $56.9(40-62)$ \\
\hline \multicolumn{2}{|l|}{ Lobe } \\
\hline Right & $182(49.3)$ \\
\hline Left & $170(46.0)$ \\
\hline Isthmus & $17(4.7)$ \\
\hline \multicolumn{2}{|l|}{ Nodule size, mm } \\
\hline Mean (range) & $17.9(4-50)$ \\
\hline \multicolumn{2}{|c|}{$\%$ of cases in TI-RADS categories } \\
\hline 2 & $144(39.0)$ \\
\hline 3 & $15(4.1)$ \\
\hline $4 \mathrm{a}$ & $166(45.0)$ \\
\hline $4 b$ & $38(10.3)$ \\
\hline 5 & $6(1.6)$ \\
\hline Total & $369(100.0)$ \\
\hline \multicolumn{2}{|c|}{$\%$ of cases in TBSRTC categories } \\
\hline ND & $63(17.1)$ \\
\hline $\mathrm{B}$ & $219(59.3)$ \\
\hline AUS/FLUS & $26(7.1)$ \\
\hline FN/SFN & $19(5.1)$ \\
\hline SFM & $10(2.7)$ \\
\hline M & $32(8.7)$ \\
\hline Total & $369(100.0)$ \\
\hline
\end{tabular}

TI-RADS, Thyroid Imaging Reporting and Data System; TBRSCT, The Bethesda System for Reporting Thyroid Cytopathology; ND, non-diagnostic; B, benign; AUS/FLUS, atypia/follicular lesion of undetermined singnificance; FN/SFN, follicular neoplasia/suspicious for follicular neoplasia; SFM, suspicious for malignancy; M, malignant.

the importance of FNA-induced changes that may give rise to false-positive results on thyroid cytology and false-negative results/understaging of the tumor on thyroid pathology (17). Unnecessary and repeat FNAs may cause what is referred to as 'external factors/changes', causing degenerative processes in the nodule through organizing hemorrhage, granulation tissue, fibrosis and sclerosis. The same cellular processes may be seen as spontaneous degenerative changes of the nodule, referred to as 'internal factors/changes' (18). All these external and internal changes of the nodule may resemble suspicious imaging findings that may easily be categorized as TI-RADS 4a (19). Overlapping US characteristics of malignant and benign nodules is an ongoing problem, despite several large-scale studies that were successful in discriminating malignancy in thyroid nodules. The results of internal and external changes of the nodule may be reflected as false-positive results in cytopathology and vanishing tumors/understaging of the tumor in pathology $(17,18)$. The amount of unnecessary FNAs has been
Table III. Distribution of cases between TI-RADS and TBSRTC.

\begin{tabular}{|c|c|c|}
\hline TBCSRTC & $\begin{array}{c}\text { No. of cases } \\
\text { in each } \\
\text { category }(\%)\end{array}$ & $\begin{array}{l}\text { Malignancy ratio } \\
\text { according to } \\
\text { Horvath et al (8) }\end{array}$ \\
\hline TI-RADS 2 & & $0 \%$ \\
\hline ND & $21(14.5)$ & \\
\hline $\mathrm{B}$ & $105(73.0)$ & \\
\hline AUS/FLUS/FN/SFN & $10(7.0)$ & \\
\hline $\mathrm{SFM} / \mathrm{M}$ & $8(5.5)$ & \\
\hline TI-RADS 3 & & $<5 \%$ \\
\hline ND & $3(20.0)$ & \\
\hline $\mathrm{B}$ & $9(60.0)$ & \\
\hline AUS/FLUS/FN/SFN & $2(13.3)$ & \\
\hline $\mathrm{SFM} / \mathrm{M}$ & $1(6.7)$ & \\
\hline TI-RADS 4a & & $5-10 \%$ \\
\hline ND & 33 (19.9) & \\
\hline B & $91(54.8)$ & \\
\hline AUS/FLUS/FN/SFN & $25(15.1)$ & \\
\hline $\mathrm{SFM} / \mathrm{M}$ & $17(10.2)$ & \\
\hline TI-RADS 4b & & $10-80 \%$ \\
\hline ND & $5(13.1)$ & \\
\hline $\mathrm{B}$ & $15(39.5)$ & \\
\hline AUS/FLUS/FN/SFN & $8(21.0)$ & \\
\hline $\mathrm{SFM} / \mathrm{M}$ & $10(26.4)$ & \\
\hline TI-RADS 5 & & $>80 \%$ \\
\hline ND & $1(16.6)$ & \\
\hline $\mathrm{B}$ & $0(0.0)$ & \\
\hline AUS/FLUS/FN/SFN & $0(0.0)$ & \\
\hline $\mathrm{SFM} / \mathrm{M}$ & $5(83.4)$ & \\
\hline
\end{tabular}

TI-RADS, Thyroid Imaging Reporting and Data System; TBRSCT, The Bethesda System for Reporting Thyroid Cytopathology; ND, non-diagnostic; B, benign; AUS/FLUS, atypia/follicular lesion of undetermined singnificance; FN/SFN, follicular neoplasia/suspicious for follicular neoplasia; SFM, suspicious for malignancy; M, malignant.

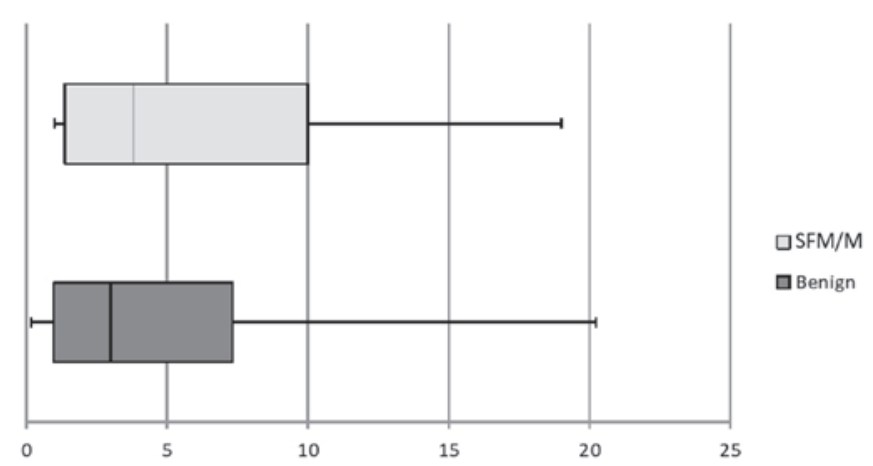

Figure 1. Box plot shows E-max values of 261 benign and malignant (SFM/M) cases. $\mathrm{x}$-axis and $\mathrm{y}$-axis demonstrate benign and malignant cases according to TBSRTC and E-max values, respectively. The lower and upper ends of vertical lines are minimum and maximum E-max values. The upper edge of both boxes are the 75th percentile of the data set; lower end represents the 25 th percentile. The line in the box shows the median. 


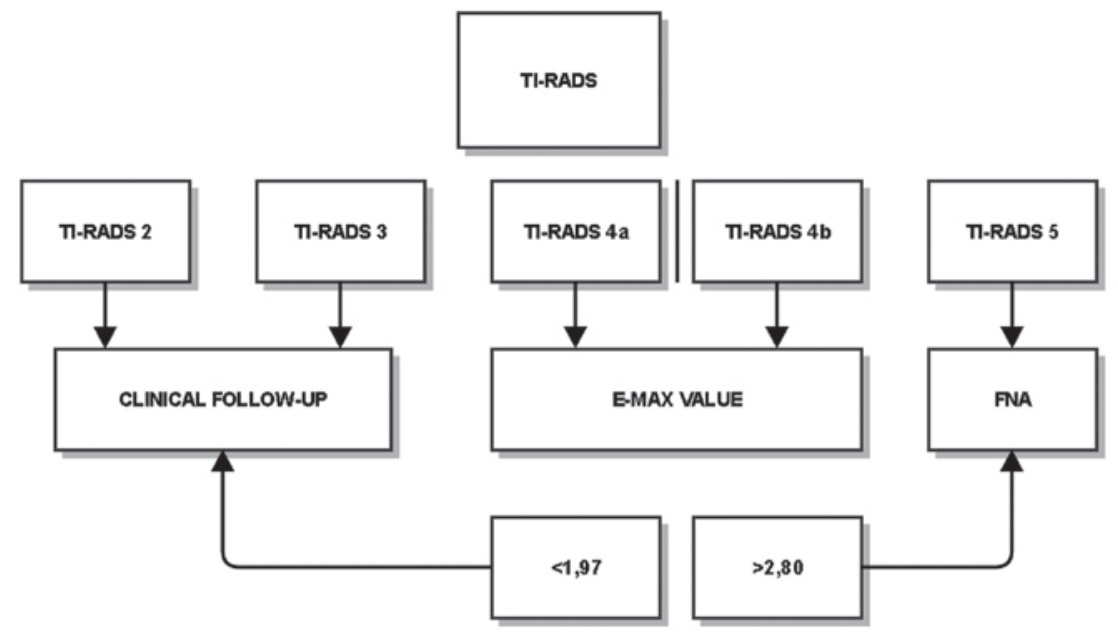

Figure 2. Process flowchart. TI-RADS, Thyroid Imaging Reporting and Data System; FNA, fine-needle aspiration.

Table IV. Limitations of strain elastography.

\begin{tabular}{ll}
\hline Technical & \multicolumn{1}{c}{ Histological } \\
\hline $\begin{array}{l}\text { Intra-/interobserver variability } \\
\text { Lack of standardization }\end{array}$ & $\begin{array}{l}\text { Thyroiditis } \\
\text { Calcification }\end{array}$ \\
$\begin{array}{l}\text { Clinical conditions of the patient: } \\
\text { Arrhytmia, aterosclerosis, }\end{array}$ & Cystic degeneration \\
hypertension & \\
Carotid artery pulsations & Isthmic localization \\
& $\begin{array}{l}\text { Nodule size } \\
\text { Follicular carcinoma } \\
\text { (due to the softness } \\
\text { of the tumor) }\end{array}$ \\
\hline
\end{tabular}

steadily increasing due to the increased detection of nodules by high resolution US. This may lead to transforming a successful diagnostic test into a screening modality, which may have legal implications and is associated with high medical costs (7). Our results demonstrated that TI-RADS 4 a must be elucidated to eliminate the overlapping characteristics of reactive changes and malignancy in this group.

Elastography has been proposed as a new dynamic technique to assess the elasticity of the nodule in comparison with the adjacent parenchyma and is a well-accepted method for the breast and prostate gland. Previously published studies suggest certain limitations based on technical and histological factors (7) (Table IV). However, several studies demonstrated the usefulness of SE in avoiding unnecessary FNA and discriminating malignant from benign nodules. The sensitivity and specificity vary from $43.2-100 \%$ up to $70-92 \%$, respectively, along with wide alterations of the positive predictive value (40-60\%); however, the most common point is the high NPV results (90-99\%) in almost all studies (20-23). Despite all its limitations, we consider SE to be a reliable method in the diagnosis of benign nodules, taking into consideration the high NPV ratios in the majority of the studies.
Although our results were presented as a scheme (Fig. 2), we do not propose an algorithm for patient management, since a group of 369 patients is not sufficiently large to suggest one. There is some agreement between TI-RADS and TBSRTC, but the high ratio of benign cytology results in categories $4 \mathrm{a}$ (54.8\%) and $4 \mathrm{~b}(39.5 \%)$ demonstrate that benign characteristics actually dominate these groups and, thus, the unnecessary biopsy rate is increased, disguising malignancy. These categories require modifications. Further studies should be performed concerning inter- and intraobserver variability, internal and external histological factors, or different imaging methods. A similar contradiction exists for ES. The E-max values demonstrate a marginally significant difference between benign and malignant nodules; however, the significant overlap over a wide range of values limit its use in daily practice.

We believe that TI-RADS, as well as E-max, may be considered for inclusion in the 3 main guidelines; however, due to the abovementioned limitations, they must be simplified/modified. TBSRTC must have a simple, reproducible US scoring system to prevent unnecessary FNAs, which may be added to the main guidelines if it proves to be a secondary success over time.

In conclusion, TI-RADS must be modified, or a new US uniform reporting system must be created in a significantly more practical and effective manner. The TI-RADS categories and SE must be reviewed to eliminate the significant existing overlap between benign and malignant cytology findings. The high rate of unnecessary biopsy for benign thyroid nodules is a worldwide problem; thus, our results demonstrate a certain benefit in discrimination compared with the current system.

\section{References}

1. Faquin WC, Bongiovanni M and Sadow PM: Update in thyroid fine needle aspiration. Endocr Pathol 22: 178-183, 2011.

2. American Thyroid Association (ATA) Guidelines Taskforce on Thyroid Nodules and Differentiated Thyroid Cancer, Cooper DS, Doherty GM, Haugen BR, Kloos RT, Lee SL, Mandel SJ, Mazzaferri EL, McIver B, Pacini F, et al: Revised American thyroid association management guidelines for patients with thyroid nodules and differentiated thyroid cancer. Thyroid 19: 1167-1214, 2009.

3. Ahn SS, Kim EK, Kang DR, Lim SK, Kwak JY and Kim MJ: Biopsy of thyroid nodules: Comparison of three sets of guidelines. AJR Am J Roentgenol 194: 31-37, 2010. 
4. Cibas ES and Ali SZ: The Bethesda system for reporting thyroid cytopathology. Thyroid 19: 1159-1165, 2009.

5. Moon HJ, Kim EK, Yoon JH and Kwak JY: Malignancy risk stratification in thyroid nodules with nondiagnostic results at cytologic examination: Combination of thyroid imaging reporting and data system and the Bethesda System. Radiology 274: 287-295, 2015.

6. Dhyani M, Faquin W, Lubitz CC, Daniels GH and Samir AE: How to interpret thyroid fine-needle aspiration biopsy reports: A guide for the busy radiologist in the era of the Bethesda classification system. AJR Am J Roentgenol 201: 1335-1339, 2013.

7. Cantisani V, Grazhdani H, Drakonaki E, D'Andrea V, Di Segni M, Kaleshi E, Calliada F, Catalano C, Redler A, Brunese L, et al: Strain US elastography for the characterization of thyroid nodules: Advantages and limitation. Int J Endocrinol 2015 908575, 2015.

8. Horvath E, Majlis S, Rossi R, Franco C, Niedmann JP, Castro A and Dominguez $\mathrm{M}$ : An ultrasonogram reporting system for thyroid nodules stratifying cancer risk for clinical management J Clin Endocrinol Metab 94: 1748-1751, 2009.

9. Park JY, Lee HJ, Jang HW, Kim HK, Yi JH, Lee W and Kim SH: A proposal for a thyroid imaging reporting and data system for ultrasound features of thyroid carcinoma. Thyroid 19: 1257-1264, 2009.

10. Ophir J, Céspedes I, Ponnekanti H, Yazdi Y and Li X: Elastography: A quantitative method for imaging the elasticity of biological tissues. Ultrasoun Imaging 13: 111-134, 1991.

11. Kwak JY and Kim EK: Ultrasound elastography for thyroid nodules: Recent advances. Ultrasonography 33: 75-82, 2014.

12. Walfish PG, Miskin M, Rosen IB and Strawbridge HT: Application of diagnostic techniques in the management of nodular goiter. Can Med Assoc J 115: 35-40, 1976.

13. Gharib H, Papini E, Paschke R, Duick DS, Valcavi R, Hegedüs L and Vitti P; AACE/AME/ETA Task Force on Thyroid Nodules: American Association of Clinical Endocrinologists, Associazione Medici Endocrinologi and European thyroid association medical guidelines for clinical practice for the diagnosis and management of thyroid nodules: Executive summary of recommendations. J Endocrinol Invest 33: 287-291, 2010.

14. Frates MC, Benson CB, Charboneau JW, Cibas ES, Clark OH, Coleman BG, Cronan JJ, Doubilet PM, Evans DB, Goellner JR, et al: Management of thyroid nodules detected at US: Society of radiologists in ultrasound consensus conference statement. Ultrasound Q 22: 231-238; discussion 239-240, 2006.
15. Kwak JY, Han KH, Yoon JH, Moon HJ, Son EJ, Park SH, Jung HK, Choi JS, Kim BM and Kim EK: Thyroid imaging reporting and data system for US features of nodules: A step in establishing better stratification of cancer risk. Radiology 260: 892-899, 2011.

16. Friedrich-Rust M, Meyer G, Dauth N, Berner C, Bogdanou D, Herrmann E, Zeuzem S and Bojunga J: Interobserver agreement of Thyroid Imaging Reporting and Data System (TI-RADS) and strain elastography for the assessment of thyroid nodules. PLoS One 8: e77927, 2013.

17. Eze OP, Cai G, Baloch ZW, Khan A, Virk R, Hammers LW, Udelsman R, Roman SA, Sosa JA, Carling T, et al: Vanishing thyroid tumors: A diagnostic dilemma after ultrasonography-guided fine-needle aspiration. Thyroid 23: 194-200, 2013.

18. Canberk S, Firat P and Schmitt F: Pitfalls in the cytological assessment of thyroid nodules. Turk Patoloji Derg 31 (Suppl 1): S18-S33, 2015.

19. Lacout A, Thariat J, Chevenet C and Marcy PY: Management of thyroid nodules on US with benign or atypical cytological features. Diagn Interv Imaging 96: 507-509, 2015.

20. Nell S, Kist JW, Debray TP, de Keizer B, van Oostenbrugge TJ, Borel Rinkes IH, Valk GD and Vriens MR: Qualitative elastography can replace thyroid nodule fine-needle aspiration in patients with soft thyroid nodules. A systematic review and meta-analysis. Eur J Radiol 84: 652-661, 2015.

21. Guazzaroni M, Spinelli A, Coco I, Del Giudice C, Girardi V and Simonetti G: Value of strain-ratio on thyroid real-time sonoelastography. Radiol Med 119: 149-155, 2014

22. Refaat R, Kamel A, Elganzory M and Awad NM: Can real-time ultrasound elastography using the color score and strain ratio differentiate between benign and malignant solitary nodules? The Egyptian Society of Radiology and Nuclear Medicine 45: 75-87, 2014

23. Wang H, Zhang S, Xin X, Zhao LH, Li CX, Mu JL and Wei XQ: Application of real-time ultrasound elastography in diagnosing benign and malignant thyroid solid nodules. Cancer Biol Med 9: $124-127,2012$ 